\title{
Coherent assessments of Europe's marine fishes show regional divergence and megafauna loss
}

\author{
Paul G. Fernandes ${ }^{1 \star}$, Gina M. Ralph ${ }^{2}$, Ana Nieto ${ }^{3}$, Mariana García Criado ${ }^{3}$, Paraskevas Vasilakopoulos ${ }^{4,5}$, \\ Christos D. Maravelias ${ }^{4}$, Robin M. Cook ${ }^{6}$, Riley A. Pollom7, Marcelo Kovačić ${ }^{8}$, David Pollard9, \\ Edward D. Farrell ${ }^{10}$, Ann-Britt Florin"11, Beth A. Polidoro ${ }^{12}$, Julia M. Lawson7, Pascal Lorance ${ }^{13}$, Franz Uiblein ${ }^{14}$, \\ Matthew Craig'15, David J. Allen³, Sarah L. Fowler ${ }^{16}$, Rachel H. L. Walls', Mia T. Comeros-Raynal2,17, \\ Michael S. Harvey ${ }^{2}$, Manuel Dureuil ${ }^{18}$, Manuel Biscoito ${ }^{19}$, Caroline Pollock ${ }^{3}$, Sophy R. McCully Phillips ${ }^{20}$, \\ Jim R. Ellis ${ }^{20}$, Constantinos Papaconstantinou ${ }^{21}$, Alen Soldo ${ }^{22}$, Çetin Keskin ${ }^{23}$, Steen Wilhelm Knudsen ${ }^{24}$, \\ Luís Gil de Sola ${ }^{25}$, Fabrizio Serena ${ }^{26}$, Bruce B. Collette ${ }^{27}$, Kjell Nedreaas ${ }^{14}$, Emilie Stump ${ }^{28}$, \\ Barry C. Russell ${ }^{29}$, Silvia Garcia ${ }^{30}$, Pedro Afonso ${ }^{31}$, Armelle B. J. Jung ${ }^{32}$, Helena Alvarez ${ }^{30}$, João Delgado ${ }^{33}$, \\ Nicholas K. Dulvy ${ }^{7}$ and Kent E. Carpenter ${ }^{2}$
}

\begin{abstract}
Europe has a long tradition of exploiting marine fishes and is promoting marine economic activity through its Blue Growth strategy. This increase in anthropogenic pressure, along with climate change, threatens the biodiversity of fishes and food security. Here, we examine the conservation status of 1,020 species of European marine fishes and identify factors that contribute to their extinction risk. Large fish species (greater than $\mathbf{1 . 5} \mathbf{~ m}$ total length) are most at risk; half of these are threatened with extinction, predominantly sharks, rays and sturgeons. This analysis was based on the latest International Union for Conservation of Nature (IUCN) European regional Red List of marine fishes, which was coherent with assessments of the status of fish stocks carried out independently by fisheries management agencies: no species classified by IUCN as threatened were considered sustainable by these agencies. A remarkable geographic divergence in stock status was also evident: in northern Europe, most stocks were not overfished, whereas in the Mediterranean Sea, almost all stocks were overfished. As Europe proceeds with its sustainable Blue Growth agenda, two main issues stand out as needing priority actions in relation to its marine fishes: the conservation of marine fish megafauna and the sustainability of Mediterranean fish stocks.
\end{abstract}

M arine fishes exhibit high biodiversity ${ }^{1,2}$ and have been culturally and nutritionally important throughout human history ${ }^{3}$. Europe, in particular, has a well-documented history of exploiting marine fish populations, written records of which commence in the classical works of ancient Greece. Although this historical exploitation has undoubtedly altered populations ${ }^{4,5}$ and changed many seascapes ${ }^{6}$, marine defaunation in the region has not been as great as in terrestrial systems ${ }^{7}$. However, the use of ocean space and resources is increasing due to Europe's Blue Growth strategy ${ }^{8}$, the nutritional requirements of an expanding human population are growing ${ }^{9,10}$ and marine ecosystems will experience unusually rapid changes in future due to climate change ${ }^{11,12}$. Consequently there are imminent threats both to European marine biodiversity and fish resources ${ }^{13}$. It is important, therefore, to assess the threats of extinction to fish species and to ensure consistency in the management approach by the various agencies involved.

We analysed data on the conservation status of 1,020 species of Europe's marine fishes from the recent International Union for Conservation of Nature (IUCN) Red List assessments ${ }^{14}$ to identify characteristics that make Europe's fishes most susceptible to extinction risk. We then compared the Red List with 115 fish stock assessments (of 31 species) made by intergovernmental agencies charged with providing advice on the exploitation of commercial fishes. Previous comparisons of this sort applied criteria under various modelling assumptions ${ }^{15-17}$ or limited the comparison to biomass reference points ${ }^{18}$.

\section{Results}

Of the 1,020 European marine fish species that were assessed, 67 (6.6\%) were threatened with extinction and 202 species (19.8\%) were assessed as Data Deficient (DD). Given that, the percentage of threatened species was estimated at $8.2 \%$, with lower and upper bounds of $6.6 \%$ and $26.4 \%$, respectively (see Methods). Of the 67 threatened species, $2.1 \%$ (21 out of 1,020 species) were Critically Endangered (CR), 2.3\% (23 species) were Endangered (EN) and 2.3\% (23 species) were Vulnerable (VU; see Supplementary Table 1). A further $2.5 \%$ (26 species) were considered Near Threatened (NT). The vast majority of species $(71.1 \%, 725$ species) were considered to be Least Concern (LC). Extinction risk in European marine fishes fell within the medium to low range compared with that of terrestrial and other aquatic species in the region ${ }^{14}$. In the eastern tropical Pacific ${ }^{19}$ and eastern central Atlantic ${ }^{20}$, the only other regions of the world where all marine fishes of the continental shelf have been assessed, $12 \%$ and $6.1 \%$ of species were assessed as threatened, respectively. In Europe, most species were assessed as threatened based on the reduction in total size of their populations (measured over the longer of ten years or three generations), whereas some were threatened due to restricted geographic range, combined with a severely fragmented 
population and a continuing decline. Others were classed as threatened due to their very small total population size. Fishing, both in targeted fisheries and as bycatch, was the most common threat to marine fishes; other threats included pollution, coastal development, climate change, energy production and mining ${ }^{14}$.

To assess which characteristics were most important in determining the vulnerability of Europe's fishes to extinction risk, we used a conditional random forest $(\mathrm{RF})^{21}$ model. The model was able to predict IUCN threat categories correctly in 757 of 818 cases where there were sufficient data (see confusion matrix in Supplementary Table 2). Taxonomic class and maximum fish size were the variables of most importance (Fig. 1a): extinction risk was greater in cartilaginous fishes (sharks, rays and chimaeras) and fishes that attained a large size. A simple classification tree (Supplementary Fig. 1) indicated that a size threshold of $149 \mathrm{~cm}$ was important in classifying threatened status. For fish species smaller than this size, 97\% (710 species) were not threatened (LC or NT). For fish species greater than or equal to this size ( 84 species), more than half (51\%, 43 species) were threatened (CR, EN or VU) and, of these, 32 were cartilaginous. Further examination revealed a significant trend in threat category with size (Fig. 1b): the larger the fish species, the more highly threatened the category.

The risk of a population or species extinction is a function of intrinsic sensitivity (biology) and exposure to an extrinsic threatening process. Hence, body size in itself is not likely to be the cause of extinction risk; rather, it is the combination of fishing mortality and body size that determines risk. Much like the terrestrial mammals of the Late Quaternary ${ }^{22}$, marine megafauna are more susceptible to population decline because they are more sought after ${ }^{23}$, and the rate at which their populations can replace themselves is low relative to the fishing mortality rate. This is due to late age at maturity, low maximum rates of population increase and (often) strong density dependence in recruitment ${ }^{24}$, which gives large fishes reduced resilience to fishing, compared with smaller species. Maximum population growth rate and related 'speed-of-life' traits may be the ultimate correlate of extinction risk, whereas body size is only the proximate, but more easily measured, correlate ${ }^{25}$. Most analyses of life history correlates have been for species within assemblages (limited geographic scale) rather than species across different assemblages. Focusing on 'speed-of-life' traits may be necessary for the latter case to control effectively for the filtering effect of temperature on the life histories of communities. Temperature drives local adaptation strongly, shaping variation in population growth rates $^{26}$, and hence may explain some of the differences in responses between cooler and warmer seas.

Clearly, the analyses presented here would have benefitted from including other life history traits, such as growth rate and related 'speed-of-life' traits, directly. However, extracting such data for all of the species considered here would be a major undertaking, because these traits are hard to measure consistently across large numbers of species. It would require an exercise akin to the Red List assessment; so here, we can only recommend these to be considered in future when such exercises are repeated. In our study, size is used as a reasonable proxy for other life history traits, which is in-keeping with other studies showing size to explain extinction risk $^{27,28}$.

Other variables in the RF were of lower importance (Fig. 1a). The binary variable 'Present in freshwater', indicating whether the species has any part of its life cycle in freshwater or not, was not particularly important. This may be because, of the 54 species that were classed as occurring in freshwater, only $11(20 \%)$ were threatened. Similarly, and somewhat unexpectedly, the binary variable 'fished', indicating whether the species was subject to fishing (including bycatch; see Methods) or not, also did not have a high importance (Fig. 1a). Of the 365 species that were fished, only 65 (18\%) were classed as threatened, and one-third (33\%) of species classed as Least Concern are fished, so fishing per se does not determine vulnerability to extinction risk. In terms of the threats to the species, fishing was by far the most ubiquitous, affecting 365 of the 818 species. The next largest threat identified was pollution, with only 54 species affected by this, but 427 species were recorded with unknown threats. The lack of information on the specific threats to fishes, other than fishing, could also be better addressed in future. This analysis does not suggest that fishing is not important, it indicates, rather, that susceptibility to extinction risk (or not) is not driven purely by this threat (because many fish species face it), but by the ability of the species

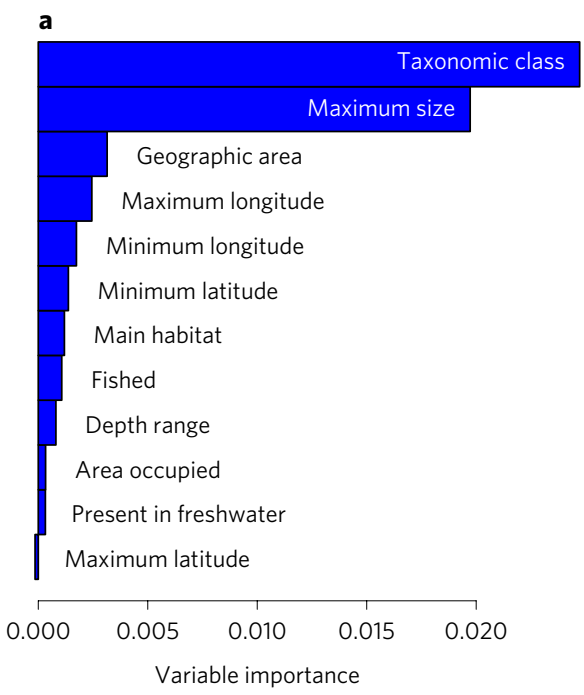

b

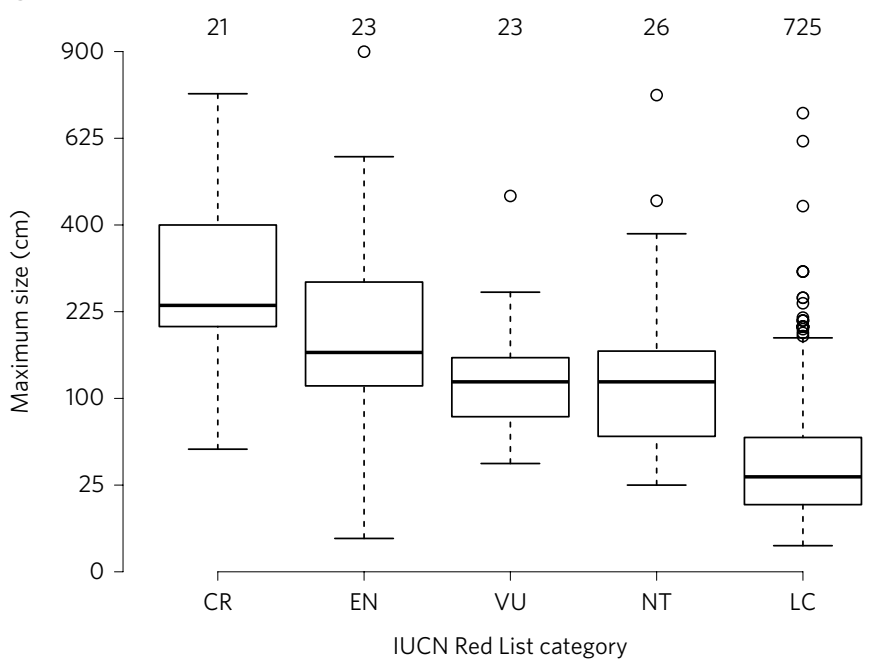

Figure 1 | Factors that affect the conservation status of European fishes. a, Variable importance plot for the conditional RF that modelled the IUCN Red List category as a function of the factors as labelled. Taxonomic class and maximum size were almost an order of magnitude more important than any other variable. b, Box plots of IUCN Red List category against size. Red List categories are Critically Endangered (CR), Endangered (EN), Vulnerable (VU), Near Threatened (NT), and Least Concern (LC). Middle band is the median, boxes indicate the interquartile range (IQR), whiskers min (max $(x), Q_{3}+1.5 x$ $I Q R)$ and $\max \left(\min (x), Q_{1}-1.5 \times I Q R\right)$, where $Q_{1}$ and $Q_{3}$ are the 1 st and 3rd quartiles respectively, and dots are outliers from the whiskers. The $L C$ category was bootstrapped 1,000 times, downsampling 26 species at random from the 725 in that category. All 1,000 bootstraps of a general linear model were significant at $P<0.0001$. The $y$ axis is on a square root scale. 


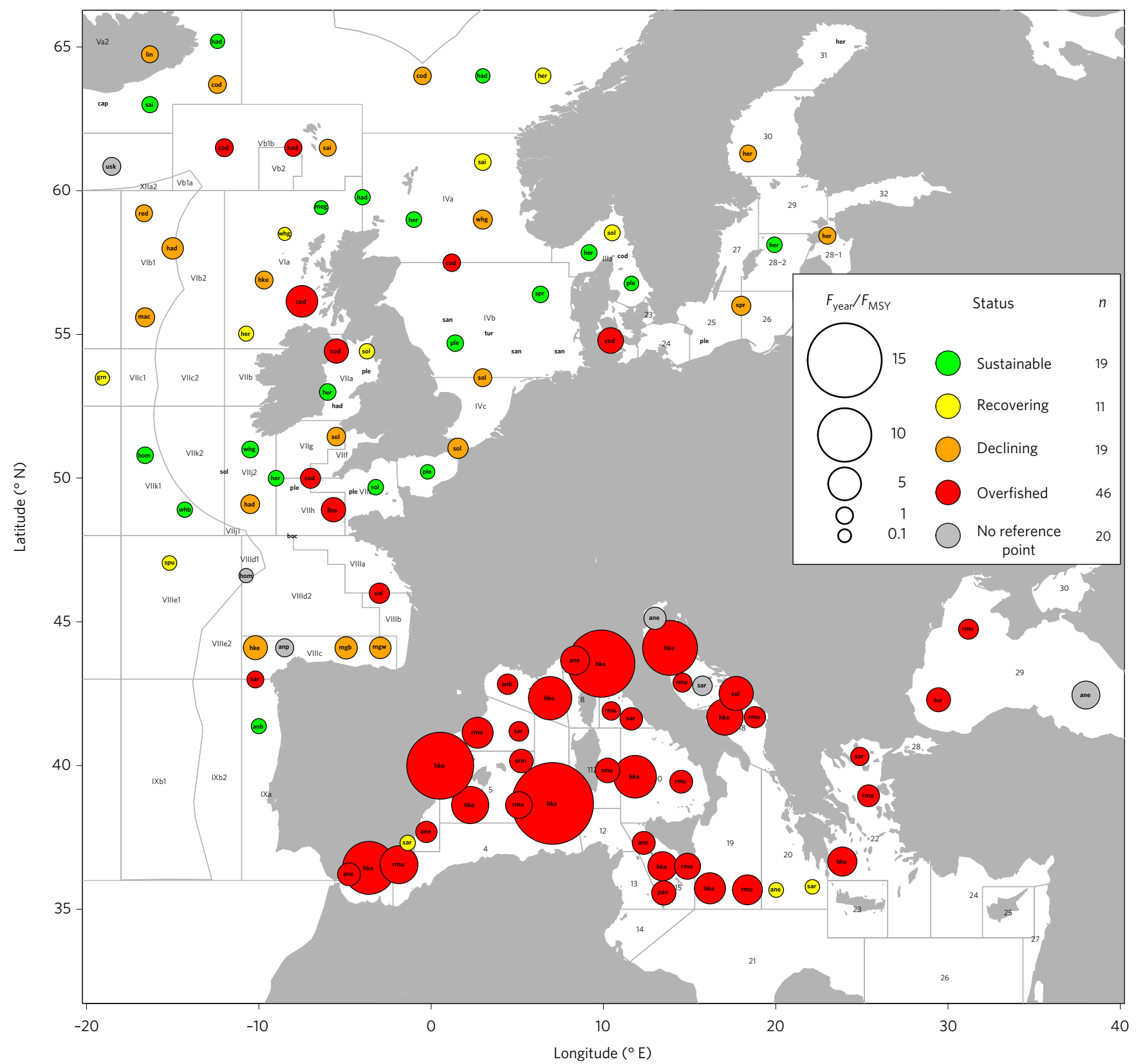

Figure 2 | Geographical distribution of the relative exploitation rate for 115 European fish stocks. The relative exploitation rate is the exploitation rate in the most recent year available $\left(F_{\text {year }}\right)$ divided by the exploitation rate consistent with MSY $\left(F_{\mathrm{MSY}}\right)$. The size of the circle is proportional to $F_{\text {year }} / F_{\mathrm{MSY}}$ and colourcoded according to status. Stocks in green are fished within sustainable limits, stocks in red are overexploited, stocks in orange are declining, while stocks in yellow are recovering. Hence, the larger the red circle the more the stock is overfished; the larger the green circle the more the stock is underfished. Grey circles indicate data on biomass are lacking (so status cannot be determined). The circles are positioned approximately according to the centre of the stock location in the General Fisheries Commission for the Mediterranean (GFCM) sub-areas and ICES divisions (numbers and roman numerals, respectively), with the exception of the ICES widely distributed stocks, which are positioned to the western edge of the continental shelf. An abbreviation for the species name is provided in the centre of each circle: anb, Lophius budegassa; ane, Engraulis encrasicolus; anp, Lophius piscatorius; boc, Boops boops; Bss, Dicentrarchus labrax; cap, Mallotus villosus; cod, Gadus morhua; grn, Coryphaenoides rupestris; had, Melanogrammus aeglefinus; her, Clupea harengus; hke, Merluccius merluccius; hom, Trachurus trachurus; lin, Molva molva; mac, Scomber scombrus; meg, Lepidorhombus spp.; mgb, Lepidorhombus boscii; mgw, Lepidorhombus whiffiagonis; pan, Pagellus erythrinus; ple, Pleuronectes platessa; red, Sebastes norvegicus; rmu, Mullus barbatus; sai, Pollachius virens; san, Ammodytidae; sar, Sardina pilchardus; sol, Solea solea; spr, Sprattus sprattus; spu, Squalus acanthias; srm, Mullus surmuletus; tur, Scophthalmus maximus; usk, Brosme brosme; whb, Micromesistius poutassou; whg, Merlangius merlangus. Stocks for which there are no reference points are abbreviated as text alone.

to counteract it. The Chondrichthyes and fishes of large size have life history traits that make them much more susceptible to high mortality rates, chief among which is fishing.

We explored the effect of commercial fishing in more detail by examining 115 stock assessments of 31 commercially exploited marine fish species in European waters. Of these, 95 assessments had enough information to determine their status (see Methods). Only 19 stocks were sustainable, with 46 being overfished, 19 declining and 11 recovering. There was a significant geographical discrepancy: a much higher fraction of the fish stocks in the Mediterranean were overexploited (Fig. 2) and depleted in biomass (Fig. 3) compared with the northeast Atlantic. Similar observations 


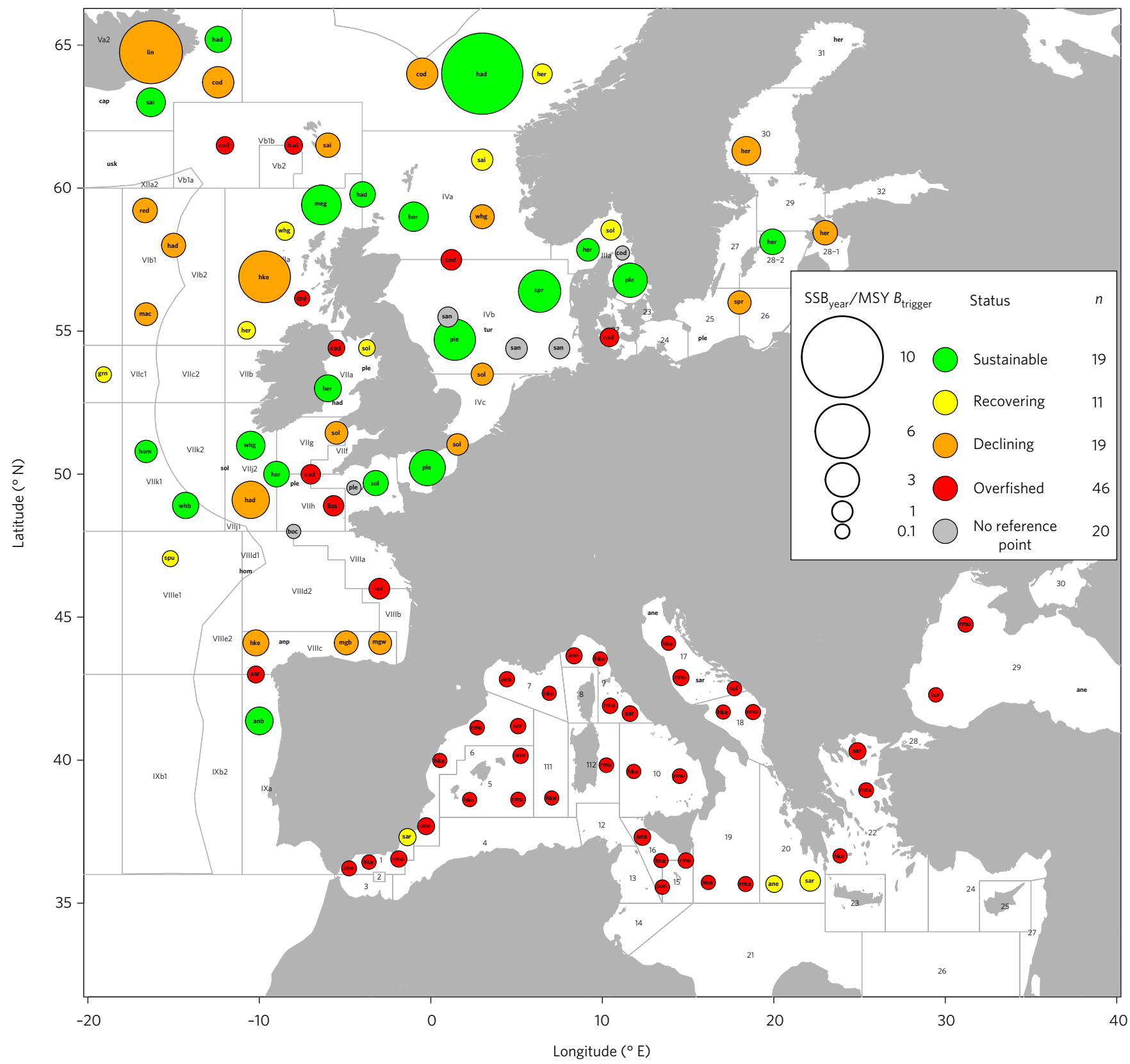

Figure 3 | Geographical distribution of the relative biomass for 115 European fish stocks. The relative biomass is the spawning stock biomass (SSB) in the most recent year available (total weight of adults, $\mathrm{SSB}_{\text {year }}$ ) divided by the biomass consistent with MSY (MSY $B_{\text {trigger }}$ ). The size of the circle is proportional to $\mathrm{SSB}_{\text {year }} / M S Y B_{\text {trigger }}$ and colour-coded according to status as per Fig. 2. Grey circles indicate data on fishing mortality are lacking (so status cannot be determined). An abbreviation for the species is provided in the centre of each circle (as per Fig. 2, along with other common elements).

have been reported before $\mathrm{e}^{29,30}$, albeit separately and in different formats for the two areas: examining both simultaneously and using the same criteria demonstrates the relative magnitude of the overfishing problem in the Mediterranean. Not one of the 39 assessed Mediterranean fish stocks examined here was classed as sustainable (Figs 2 and 3; Supplementary Table 4). Hake (Merluccius merluccius) is particularly problematic: of the 12 examined hake stocks in the Mediterranean, 9 have exploitation rates that are more than 5 times the rate that is consistent with maximum sustainable yield (MSY). Biomass estimates show a similar discrepancy: only one Mediterranean stock has more than half of the biomass that would be consistent with sustainable levels, while 15 Mediterranean stocks have less than $5 \%$ of that biomass. Compared with the northeast Atlantic, the warmer Mediterranean would be expected to have fish assemblages that reach smaller maximum sizes and have faster population growth rates $^{31}$, so populations and species should be able to recover from severe overfishing ${ }^{32}$. Our findings are, therefore, contra to these metabolic expectations, which may explain why Mediterranean fish populations have avoided complete collapse in the face of such severe overfishing. It should also be noted that the Mediterranean is a semi-enclosed sea with a much longer history of human impacts compared with the Atlantic. At present, the Mediterranean is heavily impacted, in addition to fishing, by multiple stressors ranging from temperature increase and acidification to habitat modification and pollution in coastal areas ${ }^{33}$.

In the northeast Atlantic, the situation continues to improve ${ }^{29}$ : of the 56 stocks there, almost twice as many are sustainable (19) as 


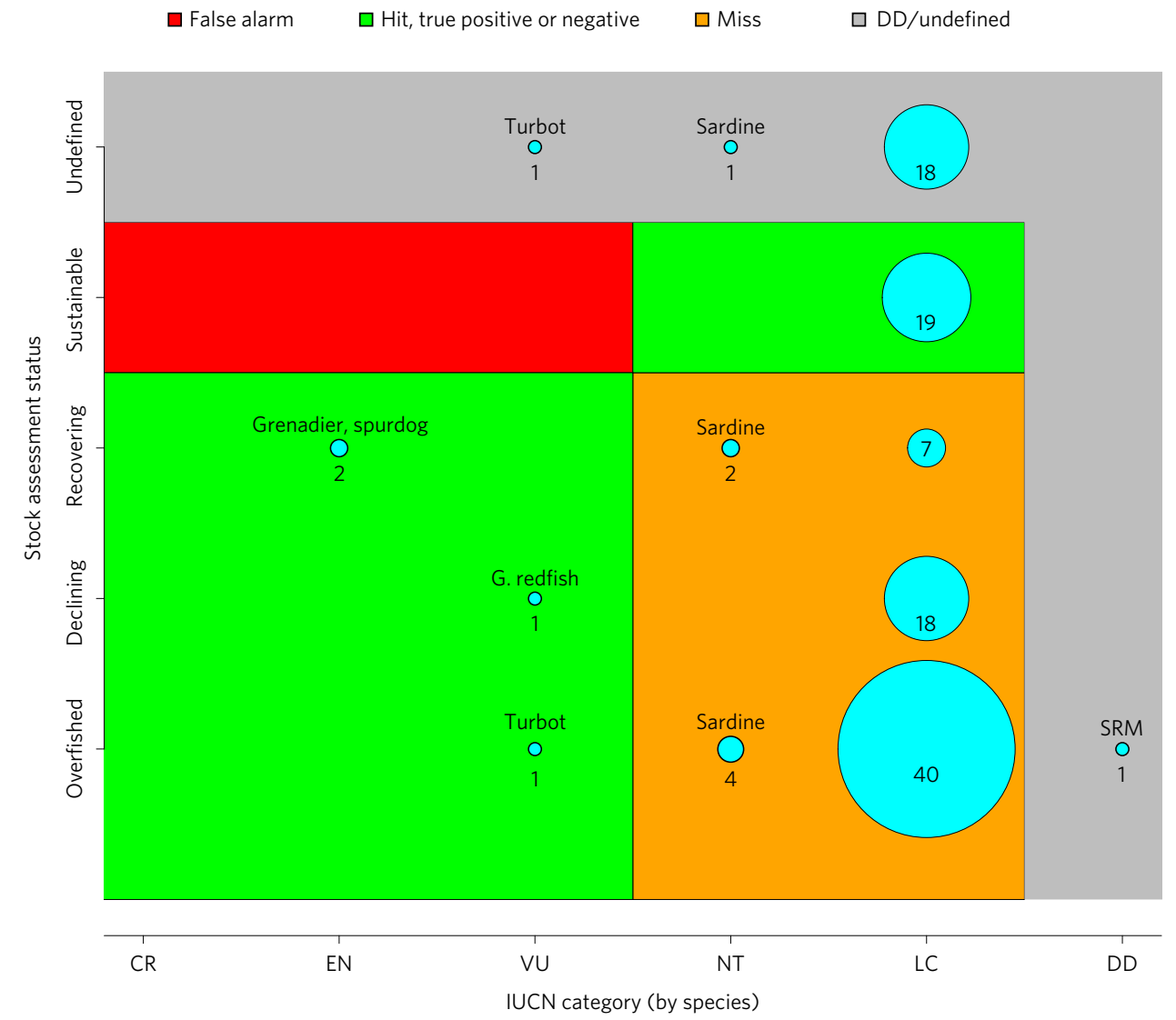

Figure 4 | Performance of the IUCN Red List in relation to stock status. Comparison of the number of stocks, classified as species according to the threat criteria of the IUCN Red List ( $x$ axis) with the stock assessment status as assessed by ICES and the GFCM ( $y$ axis) and classed according to criteria in Supplementary Table 3. Red List categories are Critically Endangered (CR), Endangered (EN), Vulnerable (VU), Near Threatened (NT), Least Concern (LC) and Data Deficient (DD). Shading indicates: hits, in green, where the two systems concur, either because a stock is not sustainable and the threat criteria are met (true positive), or because a stock is sustainable and the threat criteria are not met (true negative); misses, in orange, where a stock is exploited unsustainably but does not meet the threat criteria; and false alarms, in red, where the stock is exploited sustainably but the threat criteria are met. Blue circle size is proportional to the number of stocks (number below or inside) corresponding to each category. Names above refer to the species (by common name, SRM is striped red mullet) in particular combinations where numbers were low (4 or less), which were all of the same species.

overfished (10); 8 stocks are recovering, but 19 are declining. The stocks in most peril are those of Atlantic cod (Gadus morhua), with some still having relatively low biomass and high exploitation rates, although there has been an improvement in North Sea cod in recent years $^{34}$. The problems here are of a different nature, with recovering stocks likely to present challenges under the new landings obligation $^{35}$ (discard ban): for example, previously scarce species with low quotas are rapidly caught as they recover, closing the mixed fishery and 'choking' quotas of other species ${ }^{36}$. It is interesting to note the status of the three stocks under Faroese jurisdiction: haddock (Melanogrammus aeglefinus) and cod were overfished, and saithe (Pollachius virens) was declining. The Faroese have their own management arrangements, unique from the Common Fisheries Policy, and manage these three stocks not by regulating catches through quotas, but by regulating effort through days at sea. Effort control, rather than catch control, is the main management tool implemented in the Mediterranean as well; hence, the poor state of stocks in both areas may imply a general inadequacy of effort controls alone to secure sustainable fisheries ${ }^{30}$. The Faroese and Mediterranean fisheries differ from the rest of Europe in several other ways, most notably the contribution of fishing to local communities, a factor that presents challenges to the implementation of fisheries management.

The IUCN Red List and fish stock assessments address different issues: IUCN is concerned with extinction risk, whereas fisheries assessments are concerned with sustainable exploitation. Clearly, if a fish stock is classified as sustainable, it may seem contradictory (though theoretically possible) for IUCN to place the species in a threatened category. In our analysis, none of the stocks classified as sustainable were placed by IUCN in a threatened category (Fig. 4). Hence sustainable fishery criteria seem to be consistent with low extinction risk. With very few exceptions, even stocks classed as overfished or subject to overfishing were placed by IUCN in low risk categories. Four species were classed in IUCN threat categories: turbot (Scophthalmus maximus) and golden redfish (Sebastes norvegicus), classed as VU; and round-nosed grenadier(Coryphaenoides rupestris) and spurdog (Squalus acanthias) classed as EN. Sardine (Sardina pilchardus) was classed as NT. Where assessments exist for stocks of all of these species, they were not classed as sustainable. The two classification schemes can, therefore, be seen as complementary graduated indicators of status, with the stock sustainability representing the first level of concern. If a stock is overfished then further examination under the IUCN framework is merited to determine if there is an extinction risk. Conversely, if a species is deemed to have a low risk of extinction (LC), it is not to say that certain local stocks may not be at risk. However, as stock assessments are updated every year and IUCN Red List assessments are much less frequent, discrepancies may yet occur. An important feature of the IUCN system is that it can be applied to species for which there is no analytical stock assessment. So it may be pertinent for Red List assessments to be appended to stock assessments, particularly in cases where those 
stocks are overfished or where data are deficient (for example, in terms of reference points or fishing mortality).

Most of Europe's commercial fish stocks are not threatened with extinction. However, most of the larger fish species are, particularly sharks and rays. In addition to these cartilaginous fishes, the large fishes that are threatened include six species of sturgeon, the northern wolffish (Anarhichas denticulatus), blue ling (Molva dipterygia), the dusky grouper (Epinephelus marginatus), the Atlantic halibut (Hippoglossus hippoglossus) and (wild) Atlantic salmon (Salmo salar); although, of these, only the sturgeons are CR. In terms of the conservation of commercially fished species, management agencies in northern Europe have succeeded in reducing fishing pressure ${ }^{29}$ and, in some cases, populations are recovering ${ }^{36}$. The food security, economic performance, and political and cultural importance of the fisheries of northern Europe are clearly significant enough to merit the substantial effort required in scientific assessment and effective compliance. Such efforts are not effective in the Mediterranean ${ }^{30}$ and are insufficient for the megafauna in both regions. Greater efforts to conserve our large fish species are essential prior to the imminent expansion of anthropogenic activity in marine space (mineral exploitation, aquaculture, renewable energy, blue biotechnology and tourism), the so called Blue Growth ${ }^{8}$. Loss of these large, ecologically important species could have extended consequences that cascade to other trophic levels ${ }^{37}$ that include important commercial species, particularly in overfished southern European stocks: this could ultimately undermine sustainable Blue Growth.

\section{Methods}

Red List assessment to assess risk of extinction. Here, we considered the Red Lis assessments of 1,020 species of Europe's marine fishes ${ }^{38}$ that were assessed as part of the IUCN Red List of marine and freshwater fishes ${ }^{14,39}$. The areas considered included the Mediterranean Sea, the Black Sea, the Baltic Sea, the North Sea and the European part of the Atlantic Ocean, including the exclusive economic zones of the Macaronesian islands belonging to Portugal and Spain. Marine and anadromous fishes with breeding populations native to or naturalized in Europe before AD 1500 were included. However, species that are primarily freshwater or catadromous were excluded as the major threats affecting them occur in the freshwater, rather than marine, environment ${ }^{39}$. Species for which occurrence within European waters could not be verified and rarely documented species, presumably waifs of populations primarily occurring outside Europe, were also excluded, as were species with a marginal occurrence within European waters.

To assess the extinction risk of each species, the IUCN Red List categories and criteria $^{40}$ and the IUCN regional guidelines ${ }^{41}$ were applied. There are nine IUCN Red List categories: Extinct (EX), Extinct in the Wild (EW), Critically Endangered (CR), Endangered (EN), Vulnerable (VU), Near Threatened (NT), Least Concern (LC), Data Deficient (DD) and Not Evaluated (NE); two additional categories, Regionally Extinct (RE) and Not Applicable (NA), are used in regional Red List assessments. Species are classed as threatened if they fall within the categories CR, EN or VU. To classify as threatened, one or more of five quantitative criteria (A-E) related to population reduction (criterion $\mathrm{A}$ ), geographic range (criterion $\mathrm{B}$ ), population size and decline (criterion $\mathrm{C}$ ), very small or restricted population (criterion D), and probability of extinction (criterion E) are examined for each species. Separate thresholds then allocate species to the individual categories based on the risk of extinction, with CR indicating an extremely high risk, EN a very high risk and VU a high risk. The NT category is for those species close to qualifying, or likely to qualify in future, as threatened. The LC category has a low risk of extinction.

Nearly all of the threatened European marine fishes were listed on the basis of population declines: 56 species were listed as threatened exclusively under criterion A, most of which were based on past population declines (criterion A2). Only seven species were listed exclusively under any other criterion, with four listed under criterion B (Alosa immaculata, Mycteroperca fusca, Pomatoschistus tortonesei and Bodianus scrofa), two under criterion C (Carcharodon carcharias and Carcharias taurus), one under criterion D (Raja maderensis) and none under criterion E. Four species were listed under two criteria: two sturgeons (Acipenser naccarii and A. sturio) were listed as CR under criteria A and B, and the two sawfishes (Pristis pectinata and P. pristis) were listed as CR under criteria A and D.

The uncertainty over the degree of threat to DD species propagates to estimates of the proportion of species threatened. IUCN generally reports three values: the lower bound, the mid-point and the upper bound. The best estimate of the proportion of threatened species (that is, the mid-point) was calculated according to $(\mathrm{CR}+\mathrm{EN}+\mathrm{VU}) /($ assessed $-\mathrm{EX}-\mathrm{DD})$. This assumes that DD species are equally as threatened as those for which there are sufficient data (that is, all non-DD species). The lower bound formula applied is $(\mathrm{CR}+\mathrm{EN}+\mathrm{VU}) /($ assessed - EX) and corresponds to the assumption that none of the DD species are threatened. The upper bound formula is $(\mathrm{CR}+\mathrm{EN}+\mathrm{VU}+\mathrm{DD}) /($ assessed $-\mathrm{EX})$ and assumes that all of the DD species are threatened.

RF model to identify factors that affect risk of extinction. In addition to assessing the regional extinction risk, the following data were compiled: taxonomic classification; habitat preferences and primary ecological requirements, including pertinent biological information where available (such as size and age at maturity, generation length, maximum size and age, and so on); major threats; conservation measures (in place and needed); and species utilization. These data were entered into the IUCN species information service during the Red List assessment process based on the scientific literature, published reports and expert opinion. Classification schemes are in development to improve consistency across taxa and regions in documenting species information; the habitat classification scheme version 3.1 and threats classification scheme version 3.2 were followed here (http://www.iucnredlist.org/technical-documents/ classification-schemes).

The relative importance of these variables in determining regional extinction risk was explored using an RF (ref. ${ }^{42}$ ). An RF algorithm is a development of the classification tree whereby bootstrapped samples of data and predictors are drawn to build many trees, with the class being determined by majority votes from all trees. Classification trees are used to predict membership of objects (in this case, species) in the classes (IUCN Red List categories) of a categorical dependent variable (extinction risk) from their measurements on one or more predictor variables ${ }^{43}$. The predictor variables were drawn from the list of compiled data described above. Classification trees are often used to analyse ecological data and have many desirable properties that are suited to such data: they deal well with nonlinear relationships between variables, high-order interactions, missing values and lack of balance; and they deliver easy graphical interpretations of complex results ${ }^{44}$. A classification tree is built by recursive partitioning of data from a 'training' sub-set of the data (approximately two-thirds of the data depending on the specific algorithm). The data in the training set are split into two groups on the basis of a binary threshold value for a particular variable; the variable and threshold that best splits the data into two groups is chosen. This process is repeated on the remaining sub-groups and repeated again until no improvement can be made to the partitioning (that is, all classes have been accounted for). In the RF, each permutation (tree) compares the true classification of the remaining one-third 'test' dataset with the tree-based classification in a confusion matrix: this 'out-of-bag' comparison gives an estimate of the prediction error rate. The importance of each variable is also assessed by looking at how much the prediction error increases when (out-of-bag) data for that variable is permuted while all others are left unchanged. The difference between a classification tree and an RF is that the forest takes the majority vote prediction of class from many $(>1,000)$ trees that are randomly permuted from the number of variables and the data from each variable. A further elaboration was to use a conditional RF (ref. ${ }^{21}$ ) to account for imbalance in the classes, and to allow for predictor variables to vary in their scale of measurement or their number of categories. The latter is particularly important to determine the variable importance (the output statistic that ranks the importance of each variable in predicting the class).

The RF model was built using the Party package ${ }^{21}$ in the $\mathrm{R}$ statistical software language ${ }^{45}$. The model took the following form:

IUCN category $=$ maximum size + depth range + main habitat + geographicarea + area occupied + minimum longitude + minimum latitude + maximum longitude + maximum latitude + taxonomic class + fished + freshwater

where maximum size $=$ continuous variable of maximum fish size in $\mathrm{cm}$ (range of 2.3-900 cm) and depth range = upper depth limit - lower depth limit (range of $0-5,998 \mathrm{~m}$ ). Main habitat = categorical variable: marine neritic; marine oceanic; marine deep benthic; marine coastal/supratidal: wetlands (inland); artificial/ aquatic \& marine; marine intertidal; unknown. Geographic area = categorical variable: occurs in Mediterranean (Med) only; eastern central Atlantic $($ ECA $)+$ Med + northeast Atlantic $($ NEA $) ;$ ECA only; ECA + NEA; Med + NEA; Arctic (Arc) + NEA; NEA only; ECA + Med; Arc + ECA + Med + NEA. Area occupied $=$ continuous variable: areal extent of generalized distribution in square metres (range $1 \times 10^{9}-3.3 \times 10^{13} \mathrm{~m}^{2}$ ), estimated in ArcGIS 10.1. Minimum longitude and latitude; maximum longitude and latitude = continuous variables in decimal degrees. Taxonomic class = categorical variable of taxonomic class (Actinopterygii, Cephalaspidomorphi, Chondrichthyes or Myxini). Fished = binary variable: fished (target or bycatch) or not. This includes species that are targeted or taken as bycatch in recreational, artisanal and/or commercial fisheries. It includes species that were historically fished and/or currently fished, but probably does not capture species that are taken in very small numbers. freshwater = binary variable to indicate if any part of the species life cycle occurs in freshwater or not. 
The model was run with 10,000 trees and weighted to account for the imbalanced dataset. Weights on each observation were 1 /number of the appropriate IUCN classification: that is, all species in LC categories were weighted $1 / 725$, those in CR $1 / 21, \mathrm{EN} 1 / 23, \mathrm{VU} 1 / 23$ and NT $1 / 26$. The results of the RF were examined using a confusion matrix (cross-tabulation of the observed and predicted classes), the derived kappa and normalized mutual information statistics ${ }^{46}$, and a plot of variable importance. Variable importance is a measure of how much the prediction error increases when data for that variable are permuted while all other variables are left unchanged ${ }^{47}$ : we used the decrease in mean accuracy, that is, permutation importance ${ }^{21}$. We also constructed a simple classification tree with the same formulation as the RF (Equation (1)).

Stock assessments. We examined 115 analytical stock assessments conducted by the International Council for the Exploration of the Sea (ICES) and the Scientific, Technical and Economic Committee for Fisheries (STECF) of the European Commission (EC), the recognized authorities that provide scientific advice to managers. Assessment data for the northeast Atlantic were provided by ICES and data from the Mediterranean were compiled from individual STECF reports. We obtained additional data from individual expert group reports of assessments of Irish Sea cod, and examined every single species in the IUCN threatened categories to determine if any stock assessments for these species were available in 2015 when the IUCN Red List was being compiled. We found additional complementary data for spurdog, golden redfish and round-nosed grenadier. We consulted the reports of STECF and ICES expert groups to obtain estimates of the two principal reference points used in providing advice. These reference points, based on the theory of MSY ${ }^{48}$, were: (1) fishing mortality at MSY $\left(F_{\mathrm{MSY}}\right.$, the exploitation rate that is consistent with achieving MSY); and (2) the spawning stock biomass (SSB) that triggers a cautious response (MSY $B_{\text {trigger, }}$, Se SSB that triggers advice to reduce exploitation rates below $F_{\mathrm{MSY}}$ ). For most stocks these MSY reference points were available; where they weren't, we used target reference points from the management plan specific to the stock where appropriate, or the precautionary reference point. No MSY $B_{\text {trigger }}$ estimates were available for Mediterranean fish stocks, so $30 \%$ of the virgin biomass was used as a proxy of MSY $B_{\text {trigger }}\left(\right.$ ref. $\left.{ }^{30}\right)$. Of the 115 stocks, this gave us 101 stocks with exploitation rate $\left(F_{\text {MSY }}\right)$ and biomass (MSY $\left.B_{\text {trigger }}\right)$ reference points, but only 95 where both were available; the stocks for which one reference point was missing were still included to show the relative exploitation rate and biomass in Figs 2 and 3, respectively. We used the most recent assessments available at the time of the IUCN exercise: in the case of the ICES data in the northeast Atlantic, 63 of the 73 assessments were carried out in 2015 reflecting the status in 2014; 8 were from 2014; and 2 were from 2013. The 42 Mediterranean assessments were earlier, with 8 reflecting status in 2012, 18 in 2011, 10 from 2010, 1 from 2009, 3 from 2008 and 2 from 2006.

For the purposes of the assessment made here, we used the definition of stock status used by Australia ${ }^{49}$ and adapted it to incorporate a knife-edge assessment of $F$ and SSB relative to the MSY biological reference points described above. As we consider two reference points, there are four possible stock states depending on whether the reference point is exceeded or not: 'sustainable', 'recovering', 'declining', 'overfished' and an 'undefined' state (see Supplementary Table 3). The desired state, for a stock to be 'sustainable', is for $F$ to be at or below $F_{\mathrm{MSY}}$ and for SSB to be at, or greater than, MSY $B_{\text {trigge }}$

There are two main distinctions between the determination of status by agencies charged with assessing commercial fish stocks (for example, ICES and STECF) and IUCN. In common with other estimates of the status of commercially exploited fishes, ICES and STECF carry out assessments on individual 'stocks' of fishes rather than individual species. A 'stock' is defined as 'a sub-set of one species having the same growth and mortality parameters, and inhabiting a particular geographic area ${ }^{50}$, so these supposedly represent biologically distinct units, but in practice they are generally distinguished by geographical management areas (Fig. 1). As described above, ICES and STECF then determine stock status by comparing estimates of the exploitation rate (fishing mortality, $F$ ) and abundance (spawning stock biomass, SSB) in relation to MSY reference points where available. IUCN, on the other hand, assesses extinction risk at the species level, which presents challenges for wide-ranging species where data might be limited. For the Red List assessments analysed here, these species assessments have been confined to the larger geographical region of Europe. Previously, there have been concerns that the IUCN Red List criteria may have overestimated the extinction risk for many exploited marine species ${ }^{15,16}$, potentially weakening the credibility of any recommendation arising from the Red List assessment to conserve those species that may be genuinely at risk.

Data availability. The datasets generated during and/or analysed during the current study are available from: ICES at http://standardgraphs.ices.dk/download/ HandlerDownload.ashx?year=2015 and http://www.ices.dk/community/advisoryprocess/Pages/Latest-Advice.aspx; STECF at https://stecf.jrc.ec.europa.eu/reports/ medbs; and the European Environment Agency (EEA) at http://www.eea.europa. eu/data-and-maps/data/european-red-lists-5.

Received 12 July 2016; accepted 19 April 2017; published 26 May 2017; corrected 12 June 2017

\section{References}

1. Beaugrand, G., Edwards, M., Raybaud, V., Goberville, E. \& Kirby, R. R. Future vulnerability of marine biodiversity compared with contemporary and past changes. Nat. Clim. Change 5, 695-701 (2015).

2. Eschmeyer, W. N., Fricke, R., Fong, J. D. \& Polack, D. A. Marine fish diversity: history of knowledge and discovery (Pisces). Zootaxa 2525, 19-50 (2010).

3. O'Connor, S., Ono, R. \& Clarkson, C. Pelagic fishing at 42,000 years before the present and the maritime skills of modern humans. Science 334, 1117-1121 (2011).

4. Lotze, H. K. \& Worm, B. Historical baselines for large marine animals. Trends Ecol. Evol. 24, 254-262 (2009).

5. Poulsen, B. The variability of fisheries and fish populations prior to industrialized fishing: an appraisal of the historical evidence. J. Marine Syst. 79, 327-332 (2010).

6. Lotze, H. K., Coll, M., Magera, A. M., Ward-Paige, C. \& Airoldi, L. Recovery of marine animal populations and ecosystems. Trends Ecol. Evol. 26, 595-605 (2011).

7. McCauley, D. J. et al. Marine defaunation: animal loss in the global ocean. Science 347, 1255641 (2015).

8. Ehlers, P. Blue growth and ocean governance-how to balance the use and the protection of the seas. WMU J. Marit. Aff. 15, 187-203 (2016).

9. Godfray, H. C. J. et al. Food security: the challenge of feeding 9 billion people. Science 327, 812-818 (2010).

10. Jennings, S. et al. Aquatic food security: insights into challenges and solutions from an analysis of interactions between fisheries, aquaculture, food safety, human health, fish and human welfare, economy and environment. Fish Fish. 17, 893-938 (2016).

11. Cheung, W. W., Watson, R. \& Pauly, D. Signature of ocean warming in global fisheries catch. Nature 497, 365-368 (2013).

12. Poloczanska, E. S. et al. Global imprint of climate change on marine life. Nat. Clim. Change 3, 919-925 (2013).

13. Halpern, B. S. et al. A global map of human impact on marine ecosystems. Science 319, 948-952 (2008).

14. Nieto, A. et al. European Red List of Marine Fishes (Publications Office of the European Union, 2015).

15. Rice, J. C. \& Legacè, È. When control rules collide: a comparison of fisheries management reference points and IUCN criteria for assessing risk of extinction. ICES J. Mar. Sci. 64, 718-722 (2007).

16. Punt, A. E. Extinction of marine renewable resources: a demographic analysis. Popul. Ecol. 42, 19-27 (2000).

17. Dulvy, N. K., Jennings, S., Goodwin, N. B., Grant, A. \& Reynolds, J. D. Comparison of threat and exploitation status in north-east Atlantic marine populations. J. Appl. Ecol. 42, 883-891 (2005).

18. Davies, T. D. \& Baum, J. K. Extinction risk and overfishing: reconciling conservation and fisheries perspectives on the status of marine fishes. Sci. Rep. 2, 561 (2012)

19. Polidoro, B. et al. Patterns of extinction risk and threat for marine vertebrates and habitat-forming species in the tropical eastern Pacific. Mar. Ecol. Prog. Ser. 448, 93-104 (2011).

20. Polidoro, B. A. et al. The status of marine biodiversity in the eastern central Atlantic (West and Central Africa). Aquat. Conserv. http://dx.doi. org/10.1002/aqc.2744 (2017).

21. Strobl, C., Boulesteix, A.-L., Zeileis, A. \& Hothorn, T. Bias in random forest variable importance measures: illustrations, sources and a solution. BMC Bioinformatics 8, 25 (2007).

22. Johnson, C. N. Determinants of loss of mammal species during the Late Quaternary 'megafauna' extinctions: life history and ecology, but not body size. Proc. R. Soc. Lon. B 269, 2221-2227 (2002).

23. Payne, J. L., Bush, A. M., Heim, N. A., Knope, M. L. \& McCauley, D. J. Ecological selectivity of the emerging mass extinction in the oceans. Science 353, 1284-1286 (2016).

24. Reynolds, J. D., Dulvy, N. K., Goodwin, N. B. \& Hutchings, J. A. Biology of extinction risk in marine fishes. Proc. R. Soc. Lon. B 272, 2337-2344 (2005)

25. Juan-Jordá, M. J., Mosqueira, I., Freire, J. \& Dulvy, N. K. Population declines of tuna and relatives depend on their speed of life. Proc. R. Soc. Lon. B 282, 20150322 (2015).

26. Jennings, S. et al. Global-scale predictions of community and ecosystem properties from simple ecological theory. Proc. R. Soc. Lon. B 275, 1375-1383 (2008).

27. Field, I. C., Meekan, M. G., Buckworth, R. C. \& Bradshaw, C. J. Susceptibility of sharks, rays and chimaeras to global extinction. Adv. Mar. Biol. 56, 275-363 (2009).

28. Olden, J. D., Hogan, Z. S. \& Zanden, M. Small fish, big fish, red fish, blue fish: size-biased extinction risk of the world's freshwater and marine fishes. Global Ecol. Biogeogr. 16, 694-701 (2007).

29. Fernandes, P. G. \& Cook, R. M. Reversal of fish stock decline in the northeast Atlantic. Curr. Biol. 23, 1432-1437 (2013). 
30. Vasilakopoulos, P., Maravelias, C. D. \& Tserpes, G. The alarming decline of Mediterranean fish stocks. Curr. Biol. 24, 1643-1648 (2014).

31. Savage, V. M., Gillooly, J. F., Brown, J. H., West, G. B. \& Charnov, E. L. Effects of body size and temperature on population growth. Am. Nat. 163, 429-441 (2004).

32. Hutchings, J. A., Myers, R. A., García, V. B., Lucifora, L. O. \& Kuparinen, A. Life-history correlates of extinction risk and recovery potential. Ecol. Appl. 22, 1061-1067 (2012).

33. Micheli, F. et al. Cumulative human impacts on Mediterranean and Black Sea marine ecosystems: assessing current pressures and opportunities. PLoS ONE 8, e79889 (2013).

34. Report of the Working Group on the Assessment of Demersal Stocks in the North Sea and Skagerrak (WGNSSK) ICES CM 2015/ACOM (ICES, 2015).

35. Borges, L. The evolution of a discard policy in Europe. Fish Fish. 16, 534-540 (2015).

36. Baudron, A. R. \& Fernandes, P. G. Adverse consequences of stock recovery: European hake, a new "choke" species under a discard ban? Fish Fish. 16, 563-575 (2015).

37. Daskalov, G. M., Grishin, A. N., Rodionov, S. \& Mihneva, V. Trophic cascades triggered by overfishing reveal possible mechanisms of ecosystem regime shifts. Proc. Natl Acad. Sci. USA 104, 10518-10523 (2007).

38. Eschmeyer, W. \& Fong, J. Catalog of Fishes (California Academy of Sciences, 2015); http://researcharchive.calacademy.org/research/ichthyology/catalog/ fishcatmain.asp

39. Freyhof, J \& Brooks, E. European Red List of Freshwater Fishes (IUCN, 2011).

40. IUCN Red List Categories and Criteria: Version 3.1. 2nd edn (IUCN Species Survival Commission, 2012).

41. Guidelines for Application of IUCN Red List Criteria at Regional and National Levels: Version 4.0 (IUCN, 2012).

42. Breiman, L. Random forests. Machine Learning 45, 5-32 (2001).

43. Breiman, L., Friedman, J. H., Olshen, R. A. \& Stone, C. J. Classification and Regression Trees (Chapman \& Hall, 1984).

44. De’ath, G. \& Fabricius, K. E. Classification and regression trees: a powerful yet simple technique for ecological data analysis. Ecology 81, 3178-3192 (2000).

45. R Core Team R: A Language and Environment for Statistical Computing (R Foundation for Statistical Computing, 2013); http://www.R-project.org/

46. Fielding, A. H. \& Bell, J. F. A review of methods for the assessment of prediction errors in conservation presence/absence models. Environ. Conserv. 24, 38-49 (1997).

47. Liaw, A. \& Wiener, M. Classification and regression by randomForest. $R$ News 2, 18-22 (2002).
48. Maunder, M. N. in Encyclopedia of Ecology (eds Sven Erik, J. \& Brian, F.) 2292-2296 (Academic, 2008).

49. Flood, M. et al. Status of Key Australian Fish Stocks Reports 2014 (Fisheries Research and Development Corporation, 2014).

50. Sparre, P. \& Venema, S. C. Introduction to Tropical Fish Stock Assessment: Part I-Manual Fisheries Technical Paper 306/1 (FAO, 1992).

\section{Acknowledgements}

P.G.F. and R.C. received funding from the Marine Alliance for Science and Technology for Scotland (MASTS) pooling initiative, funded by the Scottish Funding Council (grant reference HR09011) and contributing institutions. The European Red List of marine fishes was a project funded by the European Commission (Directorate General for the Environment under service contract number 070307/2011/607526/SER/B.3)

\section{Author contributions}

P.G.F. drafted the text, conducted the RF analysis, and produced all the figures and Supplementary Tables 2, 3 and 4. P.G.F., K.E.C., G.M.R., A.N. and M.G.C. were responsible for determining content and discussion of analyses. A.N. coordinated the European Red List of marine fishes project and K.E.C. manages IUCN's Marine Biodiversity Unit. Red List workshops and assessment reviews were organized and coordinated by K.E.C., N.K.D., J.M.L., R.A.P., G.M.R. and R.W. G.M.R. compiled the variables used in the RF analysis, and drafted components of the main text and methods. A.N. and M.G.C. drafted components of the main text and methods, and together with G.M.R. composed Supplementary Table 1. P.V., C.D.M., R.M.C., N.K.D., R.A.P., M.K., D.P., E.D.F., A.B.F., B.A.P., J.M.L., P.L. and F.U. edited drafts. All authors (except C.D.M. and P.V.) participated in Red List workshops and/or contributed to the IUCN assessments. P.V. and C.D.M. collated the Mediterranean stock assessment data.

\section{Additional information}

Supplementary information is available for this paper.

Reprints and permissions information is available at www.nature.com/reprints. Correspondence and requests for materials should be addressed to P.G.F.

How to cite this article: Fernandes, P. G. et al. Coherent assessments of Europe's marine fishes show regional divergence and megafauna loss. Nat. Ecol. Evol. 1, 0170 (2017).

Publisher's note: Springer Nature remains neutral with regard to jurisdictional claims in published maps and institutional affiliations.

\section{Competing interests}

The authors declare no competing financial interests.

'School of Biological Sciences, University of Aberdeen, Aberdeen AB24 2TZ, UK. ${ }^{2}$ IUCN Marine Biodiversity Unit, Department of Biological Sciences, Old Dominion University, Norfolk, Virginia 23529-0266, USA. ${ }^{3}$ Global Species \& Key Biodiversity Areas Programme IUCN, Rue Mauverney 28, 1196 Gland, Switzerland. ${ }^{4}$ Institute of Marine Biological Resources and Inland Waters, Hellenic Centre for Marine Research (HCMR), 46.7 km Athens-Sounio Avenue, 19013 Anavyssos, Greece. ${ }^{5}$ European Commission, Joint Research Centre, Directorate D - Sustainable Resources, Unit D.02 Water and Marine Resources, Via Enrico Fermi 2749, 21027 Ispra (VA), Italy. ${ }^{6}$ Department of Mathematics and Statistics, University of Strathclyde, 26 Richmond Street, Glasgow G1 1XH, UK. 7 IUCN Shark Specialist Group and Earth to Ocean Research Group, Department of Biological Sciences, Simon Fraser University, 8888, University Drive, Burnaby, British Columbia V5A 1S6, Canada. ${ }^{8}$ Natural History Museum Rijeka, Lorenzov prolaz 1, HR-51000 Rijeka, Croatia. ${ }^{9}$ Department of Ichthyology, Australian Museum, 1 William Street, Sydney, New South Wales 2010, Australia. ${ }^{10}$ School of Biology \& Environmental Science, University College Dublin, Belfield, Dublin 4, Ireland. "Department of Aquatic Resources, Swedish University of Agricultural Sciences, Skolgatan 6, 74242 Öregrund, Sweden. ${ }^{12}$ School of Mathematics and Natural Sciences, Arizona State University, Glendale, Arizona 85306, USA. ${ }^{13}$ Institut Français de Recherche pour I'Exploitation de la Mer (Ifremer), BP 21105, 44311 Nantes cedex 3, France. ${ }^{14}$ Institute of Marine Research, Nordnesgaten 33, PO Box 1870 Nordnes, N-5817 Bergen, Norway. ${ }^{15}$ National Marine Fisheries Service, Southwest Fisheries Science Center, 8901 La Jolla Shores Drive, La Jolla, California 92037, USA. ${ }^{16}$ The Shark Trust, 15 Bakers Place Plymouth PL1 4LX, UK. ${ }^{17}$ American Samoa Environmental Protection Agency, Pago Pago, American Samoa 96799, USA. ${ }^{18}$ Department of Biology, Dalhousie University, Halifax NS B3H 4R2, Canada. ${ }^{19}$ Museu de História Natural do Funchal, Rua da Mouraria, $319004-$ 546 Funchal, Madeira, Portugal. ${ }^{20}$ Centre for Environment, Fisheries \& Aquaculture Science (Cefas), Lowestoft NR33 OHT, UK. ${ }^{21} 17$ Kolokotroni str., 15236 , Penteli Greece. ${ }^{22}$ Department of Marine Studies, University of Split, Livanjska 5, 21000 Split, Croatia. ${ }^{23}$ Faculty of Fisheries, University of Istanbul, Ordu St. No: 200, 34134 Fatih, Istanbul, Turkey. ${ }^{24}$ Natural History Museum of Denmark, University of Copenhagen, Universitetsparken 15, 2100-DK Copenhagen $\varnothing$, Denmark. ${ }^{25}$ Instituto Español de Oceanografía, Centro Costero de Málaga, 29640 Fuengirola, Spain. ${ }^{26}$ Institute for the Coastal Marine Environment of the Italian National Research Council (CNR-IAMC), 91026 Mazara Del Vallo, Italy. ${ }^{27}$ National Marine Fisheries Service Systematics Laboratory, National Museum of Natural History, Washington DC 20560, USA. ${ }^{28}$ Institute for the Oceans and Fisheries, The University of British Columbia, 2202 Main Mall, Vancouver, British Columbia V6T 1Z4, Canada. ${ }^{29}$ Museum \& Art Gallery of the Northern Territory, Darwin, Northern Territory 0810, Australia. ${ }^{30}$ Oceana Europe, Gran Via 59, 28013 Madrid, Spain. ${ }^{31}$ Institute of Marine Research/Marine and Environmental Sciences Centre. University of the Azores, $9901-862$ Horta, Portugal. ${ }^{32}$ Des Requins et Des Hommes (DRDH), BLP/Brest-Iroise, 15 rue Dumont d'Urville, Plouzané 29860, France. ${ }^{33}$ Secretaria Regional do Ambiente e Recursos Naturais, Rua Dr. Pestana Júnior, nº 6 - 5 Andar 9064-506 Funchal, Madeira, Portugal. *e-mail: fernandespg@abdn.ac.uk 


\section{Corrigendum: Coherent assessments of Europe's marine fishes show regional divergence and megafauna loss}

Paul G. Fernandes, Gina M. Ralph, Ana Nieto, Mariana García Criado, Paraskevas Vasilakopoulos, Christos D. Maravelias, Robin M. Cook, Riley A. Pollom, Marcelo Kovačić, David Pollard, Edward D. Farrell, Ann-Britt Florin, Beth A. Polidoro, Julia M. Lawson, Pascal Lorance, Franz Uiblein, Matthew Craig, David J. Allen, Sarah L. Fowler, Rachel H. L. Walls, Mia T. Comeros-Raynal, Michael S. Harvey, Manuel Dureuil, Manuel Biscoito, Caroline Pollock, Sophy R. McCully Phillips, Jim R. Ellis, Constantinos Papaconstantinou, Alen Soldo, Çetin Keskin, Steen Wilhelm Knudsen, Luís Gil de Sola, Fabrizio Serena, Bruce B. Collette, Kjell Nedreaas, Emilie Stump, Barry C. Russell, Silvia Garcia, Pedro Afonso, Armelle B. J. Jung, Helena Alvarez, João Delgado, Nicholas K. Dulvy and Kent E. Carpenter

Nature Ecology \& Evolution 1, 0170 (2017); published 26 May 2017; corrected 12 June 2017.

In the original version of this Article, the European Commission was mistakenly included as an affiliation for Christos D. Maravelias. His contribution to this work was exclusively completed while at the Hellenic Centre for Marine Research. All versions of the Article have been corrected. 